Original Article

\title{
Evaluating the impact of operating a falls prevention community of practice on falls in a residential aged care setting
}

\author{
*Jacqueline Francis-Coad ${ }^{1,2}$, Terry Haines ${ }^{3}$, Christopher Etherton-Beer ${ }^{4}$, Debbie Nobre ${ }^{5}$, Anne-Marie Hill ${ }^{2,6}$ \\ ${ }^{1}$ School of Physiotherapy, University of Notre Dame Australia, Fremantle, Western Australia \\ ${ }^{2}$ Institute for Health Research, University of Notre Dame Australia, Fremantle, Western Australia \\ ${ }^{3}$ Monash University / Monash Health Allied Health Research Unit, Melbourne, Victoria \\ ${ }^{4}$ School of Medicine and Pharmacology, University of Western Australia, Crawley, Western Australia \\ ${ }^{5}$ Brightwater Care Group, Osborne Park, Western Australia \\ ${ }^{6}$ School of Physiotherapy and Exercise Science, Curtin University, Bentley, Western Australia
}

\section{*Correspondence}

Jacqueline Francis-Coad

School of Physiotherapy, University

of Notre Dame Australia

E-mail:

jacqui.francis-coad@nd.edu.au

Received 22 July 2016

Accepted 8 February 2017

D0I: 10.24816/jcgg.2017.v8i4.03

\section{Keywords}

accidental falls

community of practice

residential aged care

\section{Abstract}

Background/Purpose: Falls are a leading adverse event in residential aged care (RAC) settings with prevention a global aim. The purpose of this study was to determine whether operating a falls prevention community of practice $(\mathrm{CoP})$ delivering evidence-based prevention interventions could change the rate of falls and injurious falls in a RAC setting.

Methods: A prospective quasi-experimental pre/post design was conducted. Participants were 13 RAC sites (779 beds) of a single RAC organization, with 20 multidisciplinary staff volunteering as $\mathrm{CoP}$ members.

Results: Falls rates pre CoP were 10.1/1,000 occupied bed days (OBD) compared with $10.9 / 1,000$ OBD post CoP operation [coefficient $0.7,95 \%$ CI $-33.5,34.9(\mathrm{p}=0.967)$ ]. This was confounded by identified differences and changes in defining falls between sites. The rate of injurious falls resulting in fractures pre CoP was 0.2/1,000 OBD compared with $0.1 / 1,000$ OBD post CoP; [coefficient -0.3, 95\% CI -1.1, $0.4(\mathrm{p}=0.423)$ ].

Conclusion: A falls prevention CoP operating for 18 months was unable to reduce falls rates in that time frame but there was a trend to a reduction in falls resulting in fracture. Additional time for implementation and evaluation of falls prevention interventions will be required in complex settings, such as RAC organizations, in the absence of additional funding. Valid comparisons of falls rates and injurious falls rates within the RAC population require the adoption of standardized definitions to improve reporting reliability.

2210-8335/Copyright (C) 2018, Asia Pacific League of Clinical Gerontology \& Geriatrics. Published by Full Universe Integrated Marketing Limited.

\section{INTRODUCTION}

Falls are a leading adverse event in the residential aged care (RAC) sector with reported rates ranging between 3-13 falls per 1,000 occupied bed days (OBD) ${ }^{1-3}$ Highly prevalent disability $(81.3 \%)$ and cognitive impairment $(68 \%)^{4}$ put this vulnerable population at high risk of falls with $50 \%$ of residents sustaining a fall within the first year of admission and $25-30 \%$ sustaining a physical injury. ${ }^{2,5}$ Australian national data demonstrate that approximately $27 \%$ of all hospital admissions for falls related injury for people aged 65 years and over were coded as being from RAC facilities, ${ }^{6}$ even though older people living 
in RAC comprise only $6 \%$ of the total older population. ${ }^{7}$

The consequences of falls have a negative impact on the RAC sector at a number of levels: for the older person physical and psychological trauma can result in loss of independence and confidence that impact their quality of life, ${ }^{2}$ for RAC facilities the additional burden of care has to be accommodated ${ }^{2,8}$ and at the health care systems level there is the financial burden with cost of a single fall in RAC conservatively estimated at $\$ 1,887$ Australian dollars (AUD). ${ }^{9}$

A limited number of studies have addressed falls prevention in the RAC population with two meta analyses presenting different key findings; the first meta-analysis of five trials found that a single intervention of supplementing residents with low vitamin D levels reduced the rate of falls by $37 \%$ (95\% CI $0.46-0.86)$ but not the risk of falling. Authors also suggested that multifactorial interventions could be effective but that evidence was inconclusive. ${ }^{10}$ The second more recent meta-analysis included trials where settings consisted of nursing homes with only caredependent residents. Meta-analysis of four trials found that multifactorial interventions significantly reduced falls by $33 \%$ as well as reducing the number of recurrent fallers by $21 \%(\mathrm{CI}=0.65-0.97){ }^{11}$

Falls prevention guidelines ${ }^{12,13}$ and falls researchers recommend that RAC facilities implement multifactorial interventions, which should be translated into practice by a multidisciplinary team, to improve falls outcomes. ${ }^{11,14}$ Australian falls prevention guidelines suggest that this involves organizations examining their practice and implementing targeted interventions according to gaps identified. ${ }^{13}$ Additionally findings from a critical literature review by Quigley et $\mathrm{al}^{14}$ proposed that the testing of future research models include falls and falls injury prevention interventions delivered at the organization, unit (facility) and resident levels. One model with the capacity to bring organizational staff together in a manner that can facilitate changes at multiple levels is a community of practice $(\mathrm{CoP})^{15,16}$ this could enable multifactorial falls prevention interventions to be successfully delivered by a RAC organization. CoPs also have the capacity to be sustainable as they allow diversification of membership and expertise, thus enabling multifactorial problems, such as falls, to be addressed from a range of perspectives and solutions actioned, ${ }^{17}$ especially where executing multi level changes is likely to take considerable time. ${ }^{11,14}$ To our knowledge there are no studies examining the impact of a community of practice on falls prevention outcomes across a RAC organization. Our study aimed to investigate the impact of a falls prevention CoP, acting at multiple levels of a RAC organization on falls rates and injurious falls (resulting in fracture) rates.

\section{METHODS}

\section{Design}

A prospective quasi-experimental pre-post design was undertaken. This study formed part of a larger project that aimed to evaluate the impact of a falls prevention CoP at organization, facility and membership levels. The larger mixed methods study collected qualitative and quantitative data and used a realist approach. Briefly, realist evaluations are utilized in healthcare particularly for complex issues, such as those in RAC settings, where an in depth understanding of how and why intervention outcomes occur is required. ${ }^{15,18}$ The protocol for the larger study is described in full elsewhere. ${ }^{16}$

\section{Participants and setting}

A 779 bed RAC provider organization with 13 geographically diverse RAC sites designated as providing general aged care and respite care participated. All sites were led by a care manager and include nursing and allied health staff that provided care in a home-like environment. General aged care services included 24 hour resident supervision, assistance with activities of daily living, medication management, meals, laundry and cleaning. Residents' diagnostic profiles included common conditions such as stroke, Parkinson's disease and heart disease. Respite care offered short term general aged care services to relieve carer burden for older people being cared for in the community. Two of these sites provided transition care, which is a short stay service designed to facilitate the transition of an older person from the acute care sector to community settings. ${ }^{19}$ Four sites also provided care for residents with complex disabilities, such as those with dementia exhibiting high levels of behavioral and psychological symptoms, Huntingdon's disease and older residents with acquired brain injury. The RAC organization employed approximately 1,185 full and part time care staff.

\section{Intervention}

A falls prevention CoP was established, piloted and then operationalized across the RAC organization. ${ }^{20}$ The falls prevention $\mathrm{CoP}$ was considered an intervention at organization level as it acted across all 13 RAC sites. Findings from the pilot study facilitated CoP operationalization and activity across the sites. For example, a key barrier identified was lower levels of staff capability using ICT, this was facilitated by staff training to enable web-based falls prevention discussion to take place amongst the membership. Members of the $\mathrm{CoP}(\mathrm{n}=20)$ who were volunteers from the RAC staff represented all 13 sites. Briefly, a CoP is a group of people who have a common interest and convene regularly to share their ideas, problem solve and collaborate to achieve negotiated goals, in this case falls prevention. ${ }^{17,21}$ The CoP met face to face three to four times annually, interacted in 11 web-based discussion forums supported by frequent email contact, to lead falls prevention audits and intervention implementation at their RAC sites. Previous studies in healthcare have identified that CoPs can be an effective means of facilitating practice change through sharing ideas including successes and failures. ${ }^{22,23}$ This may enable them to prioritize what and how falls prevention interventions should be actioned to effect change. All 13 RAC sites $(100 \%)$ completed a falls prevention activity 
audit. Falls prevention activities prioritized by the CoP from audit findings, which were all directed towards translating falls prevention evidence into practice, included writing a falls prevention policy, re-designing falls risk assessments (implemented at organization level), improving the proportion of residents supplemented with vitamin D at all 13 sites $(100 \%)$, and designing falls prevention education (8 sites $[70 \%]$ participated) have been described and evaluated elsewhere. $^{20}$

\section{Outcome measures}

The outcome measures prospectively defined were resident rate of falls per 1,000 occupied bed days, resident rate of injurious falls resulting in fracture per 1,000 occupied bed days and the proportion of residents who fell one or more times during the study observation period. These outcomes are recommended for use in falls research ${ }^{10}$ by falls research guidelines. ${ }^{24}$ Occupied bed days (calculated using the facility census) represented the denominator and number of falls the numerator multiplied by 1,000 .

A fall was defined by the researchers as any event recorded in the electronic clinical incident report as a fall and all falls recorded in the electronic system during the study observation period were included in the falls outcome data set. The organization had no pre-determined fall definition in their policy, but all sites were instructed to report falls into the electronic system.

The organization had no organization wide injurious fall classification. An injurious fall was defined as an event recorded in the electronic clinical incident report categorized as resulting in a fracture or sentinel event. All injurious falls resulting in fractures were also recorded in a separate section of the clinical incident reporting system, as they all resulted in the resident being transferred to hospital.

A person who fell was defined as a resident who was recorded in the organization's electronic clinical incident report system as sustaining one or more falls during the study observation period of three years. Electronic falls data records from each RAC site were combined at organizational level.

\section{Procedure}

The study periods in establishing and operating the $\mathrm{CoP}$ are shown in Table one, each period lasted six months. The control period of the study, period one and two, provided 12 months data prior to the CoP becoming operational. During period three the CoP met via web-based discussion forums supported by face to face meetings to plan and conduct a falls prevention audit identifying gaps in practice. ${ }^{20}$ In periods four, five and six the CoP developed and implemented falls prevention activities, where the CoP determined the timing and type of interventions that occurred (Table 1).

\section{Statistical analysis}

The demographic characteristics of the 13 RAC sites and of the residents present at any site during one or more of the six periods of the study were summarized using descriptive statistics. The proportion of residents who fell during the study was calculated by finding the percentage of residents who fell one or more times, out of the total number of residents present for one or more days at any facility. The falls rates and fracture rates for each period of the study were calculated by dividing the number of falls or fractures during each period of the study by the number of occupied bed days for that period. Site rates of falls were also calculated using the same approach.

Mixed-effects, multilevel, linear regression using site as a random effect and pre vs post intervention periods as a fixed effect was used to compare the rates of falls between these periods. One summative data point for each outcome was considered for each site-period time point in these analyses. A Gaussian distribution was employed for these analyses as the summative falls data of this nature reflected a normal

Table 1. Periods of the trial and the establishment of the falls prevention community of practice

\begin{tabular}{|c|c|c|}
\hline Six monthly measurement periods & CoP activity at RAG site level & CoP activity at RAC organizational level \\
\hline 1 (Jan 2013 - Jun 2013) & Pre CoP establishment & Pre CoP establishment \\
\hline 2 (Jul 2013 - Dec 2013) & & $\begin{array}{l}\text { Establishment of the CoP. Testing feasibility of } \\
\text { operating a CoP using web-based technology }\end{array}$ \\
\hline 3 (Jan 2014 - Jun 2014) & $\begin{array}{l}\text { CoP preparation and conduction of falls prevention } \\
\text { clinical audit across all sites. }\end{array}$ & $\begin{array}{l}\text { CoP official launch and commencement of } \\
\text { operation }\end{array}$ \\
\hline 4 (Jul 2014 - Dec 2014) & $\begin{array}{l}\text { Differences in falls reporting across sites identified. } \\
\text { Interventions planned as priority implementation } \\
\text { (post audit) }\end{array}$ & $\begin{array}{l}\text { Clarifying what constitutes a fall, definition } \\
\text { implemented. New falls policy and risk } \\
\text { assessment discussed with stakeholder groups. } \\
\text { CoP educational newsletter implemented }\end{array}$ \\
\hline 5 (Jan 2015 - Jun 2015) & $\begin{array}{l}\text { Vitamin D supplementation promoted, care } \\
\text { staff and residents surveyed re falls prevention } \\
\text { education needs }\end{array}$ & $\begin{array}{l}\text { New falls prevention policy and risk assessment } \\
\text { (with aligned management plan) iteratively } \\
\text { drafted }\end{array}$ \\
\hline 6 (Jul 2015 - Dec 2015) & $\begin{array}{l}\text { Revised risk assessment (with aligned } \\
\text { management plan) piloted. Staff and resident falls } \\
\text { prevention poster checklist developed }\end{array}$ & $\begin{array}{l}\text { New injurious falls classification reporting } \\
\text { implemented Aug } 2015 \text {. New falls prevention } \\
\text { policy made available online }\end{array}$ \\
\hline
\end{tabular}


distribution rather than the negative binomial distribution conventionally used in patient-level analyses. The preintervention period was considered to include periods one and two, while the post-intervention period included periods four, five and six. Period three falls data were not included in these analyses as they were treated as a wash in effect period. All analyses were adjusted for mean age of residents present at each site during each period and the proportion of residents present at each site during each period with cognitive impairment as fixed effects. Results were presented using coefficients and 95\% confidence intervals with an alpha of $<0.05$ considered significant.

We further explored a site-by-intervention interaction effect to examine possible treatment effect heterogeneity. The effect of the intervention at each site was examined individually by including a site (random) by intervention (fixed) interaction effect in the analyses. We then extracted the best linear unbiased predictor of this effect at each site and presented these with $90 \%$ confidence intervals given the reduced statistical power of interaction effects. All statistical analyses were completed using Stata 14 (Stata SES Texas).

\section{Protocol amendments}

It was planned to adjust analyses for residents' level of care as classified by the Australian Government aged-care funding instrument (ACFI) care rating, however this adjustment was not completed. This measure did not remain stable during the periods of the study, as residents were re-classified more than once and within each resident care rating multiple individual changes to some items meant that the overall classification changed during more than one period of the study. We did not pursue analyses investigating the impact of the intervention on the percentage of residents who had a fall during each time period. This was because of variation in the number of beds being allocated to transitional or respite care over the follow-up. An increase in these beds accompanied by rapid turn-over of residents using them increases the denominator when examining the percentage of residents who fall, giving the appearance of a decrease in this outcome. So we instead focused analyses on the rate of falls per 1,000 occupied beds days that is not affected by these changes in the same way.

\section{Ethical considerations}

Ethical approval for the study was obtained from the University of Notre Dame Human Research Ethics Committee (reference number $013145 \mathrm{~F})$. The board of the RAC organization also approved the study. All CoP members/staff provided written consent to participate.

\section{RESULTS}

There were 3,819 admissions during the study period of which 3,015 were unique admissions and 804 were multiple admissions. The mean age of residents on admission across all sites was 80.8 years (SD 10.4), $1293(42.9 \%)$ were male and 1,708 $(56.7 \%)$ were female (gender data were missing for 14 residents). The mean LOS was 433.2 days (SD, 850.5 days) while the median length of stay (LOS) was 57 days (IQR 19-387). The demographic characteristics of the residents by site and of the sites is presented in Table 2 .

There were 10,763 falls and 137 fractures across all 13 RAC sites during the three years (control and intervention periods) of the study. There were $1,432(47.5 \%)$ residents who fell during the study period. Of those, 476 (33.2\%) sustained a single fall whilst $956(66.8 \%)$ had more than one fall (range 2-193 falls). Two hundred and fourteen residents sustained two falls, 142 sustained three falls, 101 sustained four falls, 378 sustained between 5-18 falls and 121 residents sustained between 19-193 falls. Falls outcomes are presented in Table 3 and falls rates across all 13 RAC sites over each period are presented in Figure 1.

There was no significant difference in either rates of falls or
Table 2. Demographic characteristics of the sites

\begin{tabular}{|c|c|c|c|c|c|}
\hline $\begin{array}{l}\text { Site } \\
\text { no }\end{array}$ & $\begin{array}{l}\text { Number } \\
\text { of beds }\end{array}$ & $\begin{array}{l}\text { Admission } \\
\text { type, } \\
n=3,819\end{array}$ & $\begin{array}{l}\text { Proportion of residents } \\
\text { with cognitive } \\
\text { impairment (\%) }\end{array}$ & $\begin{array}{l}\text { Mean } \\
\text { age } \\
\text { (years) }\end{array}$ & $\begin{array}{l}\text { LOS', days, } \\
\text { median (range) }\end{array}$ \\
\hline 1 & 60 & $\begin{array}{c}\mathrm{GAC}^{\mathrm{a}} 79 \\
\mathrm{TC}^{\mathrm{d}} 548 \\
\mathrm{RC}^{\mathrm{c}} 10\end{array}$ & 56.9 & 81.3 & $41(1-5,421)$ \\
\hline 2 & 33 & $\begin{array}{c}\mathrm{GAC}^{\mathrm{a}} 50 \\
\mathrm{RC}^{\mathrm{c}} 85\end{array}$ & 50.5 & 85.9 & $14(1-3,575)$ \\
\hline 3 & 30 & $\begin{array}{c}\mathrm{GAC}^{\mathrm{a}} 50 \\
\mathrm{RC}^{\mathrm{c}} 1\end{array}$ & 61.2 & 82.4 & $1124(4-4,429)$ \\
\hline 4 & 20 & $\begin{array}{c}\mathrm{GAC}^{\mathrm{a}} 35 \\
\mathrm{RC}^{\mathrm{c}} 2\end{array}$ & 58.3 & 86.9 & $957(25-5,430)$ \\
\hline 5 & 64 & $\begin{array}{l}\mathrm{GAC}^{\mathrm{a}} 40 \\
\mathrm{TC}^{\mathrm{d}} 1251 \\
\mathrm{RC}^{\mathrm{c}} 54\end{array}$ & 58.7 & 81.8 & $41(1-3,318)$ \\
\hline 6 & 110 & $\begin{array}{c}\mathrm{GAC}^{\mathrm{a}} 237 \\
\mathrm{RC}^{\mathrm{c}} 165\end{array}$ & 62.6 & 81.8 & $132(3-4,199)$ \\
\hline 7 & 62 & $\begin{array}{c}\mathrm{GAC}^{\mathrm{a}} 117 \\
\mathrm{RC}^{\mathrm{c}} 69\end{array}$ & 59.6 & 74.6 & $207(1-7,176)$ \\
\hline 8 & 61 & $\begin{array}{c}\mathrm{GAC}^{\mathrm{a}} 120 \\
\mathrm{RC}^{\mathrm{c}} 10\end{array}$ & 72.6 & 74.8 & $579(2-5,869)$ \\
\hline 9 & 50 & $\mathrm{GAC}^{\mathrm{a}} 97$ & 83.9 & 78.7 & $834(14-5,862)$ \\
\hline 10 & 30 & $\begin{array}{c}\mathrm{GAC}^{\mathrm{a}} 51 \\
\mathrm{RC}^{\mathrm{c}} 2\end{array}$ & 67.3 & 77.0 & $1109(1-4,392)$ \\
\hline 11 & 131 & $\begin{array}{c}\mathrm{GAC}^{\mathrm{a}} 278 \\
\mathrm{RC}^{\mathrm{c}} 92\end{array}$ & 66.7 & 82.0 & $360(1-3,768)$ \\
\hline 12 & 61 & $\begin{array}{c}\mathrm{GAC}^{\mathrm{a}} 119 \\
\mathrm{RC}^{\mathrm{c}} 71\end{array}$ & 81.4 & 74.8 & $162.5(1-5,645)$ \\
\hline 13 & 65 & $\begin{array}{c}\mathrm{GAC}^{\mathrm{a}} 119 \\
\mathrm{RC}^{\mathrm{c}} 67\end{array}$ & 98.9 & 75.7 & $335(1-4,439)$ \\
\hline
\end{tabular}


Table 3. Falls outcomes pre and post operationalization of the CoP

\begin{tabular}{|c|c|c|c|}
\hline Site & $\begin{array}{l}\text { Periods } \\
\text { pre GoP - post CoP }\end{array}$ & $\begin{array}{l}\text { Falls, } \\
n=107,63\end{array}$ & $\begin{array}{l}\text { Fractures, } \\
n=137\end{array}$ \\
\hline 1 & $\begin{array}{l}1-3 \\
4-6\end{array}$ & $\begin{array}{l}188 \\
283\end{array}$ & $\begin{array}{l}2 \\
5\end{array}$ \\
\hline 2 & $\begin{array}{l}1-3 \\
4-6\end{array}$ & $\begin{array}{c}84 \\
122\end{array}$ & $\begin{array}{l}4 \\
4\end{array}$ \\
\hline 3 & $\begin{array}{l}1-3 \\
4-6\end{array}$ & $\begin{array}{c}120 \\
86\end{array}$ & $\begin{array}{l}1 \\
4\end{array}$ \\
\hline 4 & $\begin{array}{l}1-3 \\
4-6\end{array}$ & $\begin{array}{l}58 \\
63\end{array}$ & $\begin{array}{l}1 \\
1\end{array}$ \\
\hline 5 & $\begin{array}{l}1-3 \\
4-6\end{array}$ & $\begin{array}{l}476 \\
538\end{array}$ & $\begin{array}{c}12 \\
4\end{array}$ \\
\hline 6 & $\begin{array}{l}1-3 \\
4-6\end{array}$ & $\begin{array}{l}848 \\
577\end{array}$ & $\begin{array}{c}18 \\
5\end{array}$ \\
\hline 7 & $\begin{array}{l}1-3 \\
4-6\end{array}$ & $\begin{array}{l}184 \\
436\end{array}$ & $\begin{array}{l}1 \\
4\end{array}$ \\
\hline 8 & $\begin{array}{l}1-3 \\
4-6\end{array}$ & $\begin{array}{l}253 \\
287\end{array}$ & $\begin{array}{l}4 \\
2\end{array}$ \\
\hline 9 & $\begin{array}{l}1-3 \\
4-6\end{array}$ & $\begin{array}{l}184 \\
206\end{array}$ & $\begin{array}{l}5 \\
2\end{array}$ \\
\hline 10 & $\begin{array}{l}1-3 \\
4-6\end{array}$ & $\begin{array}{l}143 \\
139\end{array}$ & $\begin{array}{l}8 \\
1\end{array}$ \\
\hline 11 & $\begin{array}{l}1-3 \\
4-6\end{array}$ & $\begin{array}{l}1,853 \\
1,167\end{array}$ & $\begin{array}{c}6 \\
13\end{array}$ \\
\hline 12 & $\begin{array}{l}1-3 \\
4-6\end{array}$ & $\begin{array}{l}430 \\
526\end{array}$ & $\begin{array}{l}5 \\
5\end{array}$ \\
\hline 13 & $\begin{array}{l}1-3 \\
4-6\end{array}$ & $\begin{array}{l}734 \\
778\end{array}$ & $\begin{array}{c}11 \\
9\end{array}$ \\
\hline
\end{tabular}

Figure 1. Falls rates across all RAC sites

30.0

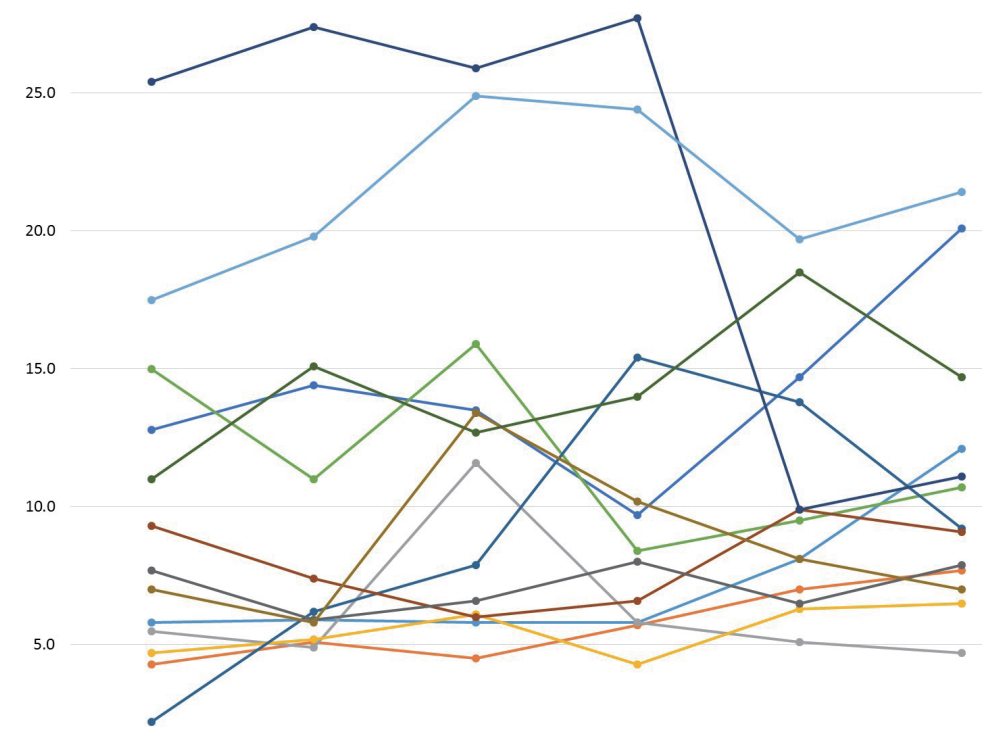

0.0

\section{Falls per 1000 Occupied Bed Days}

$$
\begin{aligned}
& \text { Period } 1 \quad \text { Period } 2 \quad \text { Period } 3 \quad \text { Period } 4 \quad \text { Period } 5 \quad \text { Period } 6
\end{aligned}
$$

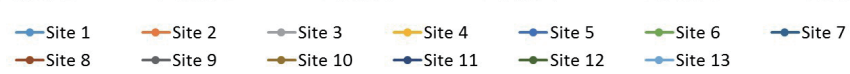

Table 4. Comparison of falls outcomes pre and post operationalization of the $\mathrm{CoP}$

\begin{tabular}{|c|c|c|}
\hline & & Coefficient, $(95 \%$ CI), p value \\
\hline $\begin{array}{l}\text { Falls rates, Pre CoP/ } \\
\text { post CoP, falls } / 1,000 \\
\text { bed days }{ }^{b}\end{array}$ & $10.1 / 10.9$ & $0.7,(-33.4,34.9), 0.967$ \\
\hline $\begin{array}{l}\text { Fracture rates, Pre } \\
\text { CoP/ post CoP, falls/ } \\
1,000 \text { bed days }\end{array}$ & $0.2 / 0.1$ & $-0.3,(-1.1,0.4), 0.423$ \\
\hline \multicolumn{3}{|c|}{$\begin{array}{l}{ }^{2} \text { All analyses adjusted for age and presence of cognitive } \\
\text { impairment; }{ }^{b} \text { Comparing periods one and two with periods four, } \\
\text { five and six. }\end{array}$} \\
\hline
\end{tabular}

fractures after the commencement of the CoP compared to the year prior to commencement, as shown in Table 4 .

The site level effect estimates demonstrated there were no significant differences in the falls rates across the different sites. The best linear unbiased predictors for each site are presented in Figure 2.

Visual inspection of these indicated the intervention may have been more effective at site 11 , but this was not significant given the width of the $90 \%$ CIs.

In regard to the injurious falls data, for the first five periods of the study only falls that resulted in a fracture (121 [1.3\%]) were required to be recorded as injurious. This meant 8,887 $(98.1 \%)$ falls were not classified as to whether they resulted in injury. At the commencement of study period six, the RAC organization changed its reporting requirements, so the 13 RAC sites had to classify falls according to the level of injury sustained. During period six $288(16.9 \%)$ falls were classified as requiring minor first aid, $172(10.1 \%)$ as causing moderate injury and $16(0.9 \%)$ as resulting in a fracture. No adverse events regarding the actions of the CoP were reported by the organization during the conduction of the study.

After the study we conducted a post hoc power analysis which indicated that we had only $10 \%$ power to detect the small standardized effect size (of 0.20) observed. Such a small effect brings the economic efficiency of this approach into question, and also indicates that we would have needed to conduct this study over a substantially greater number of sites in order to find this magnitude of effect as being statistically significant. However the time and resources required to conduct this study meant we were unable to enroll any more organizations for the purposes of our study.

\section{DISCUSSION}

The overall falls rate reported in our study 
Figure 2. Best linear unbiased predictors for each site

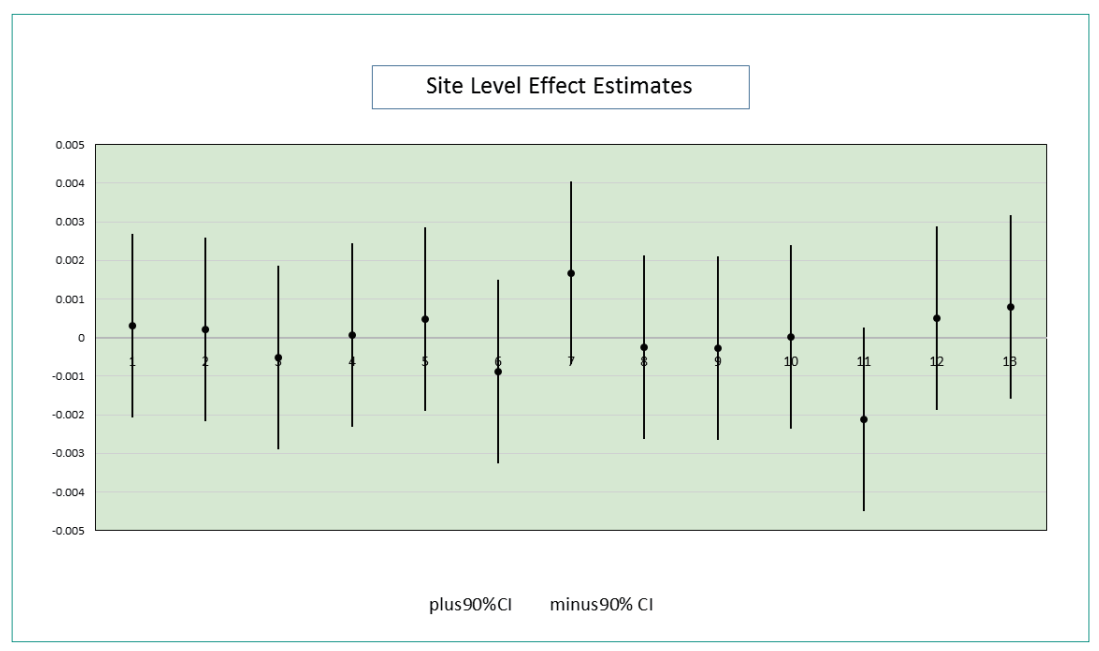

had autonomy prioritizing falls prevention activity at their sites implementation impact was less uniform, as reported by a study similarly involving RAC staff in the research process. $^{27}$

Our falls reporting changed during the study, as reporting varied between RAC sites prior to the implementation of an organization wide fall definition, with periods five and six showing the more uniform effect of standardized reporting on falls rates. A large proportion of falls were not classified as to whether they resulted in injury other than fracture until period six. Consistency in reporting falls is important ${ }^{24,27}$ particularly for RAC organizations choosing to make reliable site comparisons to learn from each other's practices.

was within the range of reported falls rates for RAC settings, ${ }^{1-3}$ however we did not demonstrate a significant difference in falls rates following the falls prevention CoP commencing operation. Like similar studies delivering multifactorial interventions at multiple levels our falls rates trended upwards. ${ }^{5,25}$ Our study showed rapid increases in the number of falls at sites one and five, this heterogeneity may be explained by the fact that they had converted to provide transition care services shortly before our study commenced. Transition care services have a maximum stay of 12 weeks with an average stay of seven weeks ${ }^{19}$ and hence these sites had considerably more admissions of older people not yet functionally recovered from acute care settings compared with than any other sites. Our study also showed a trend towards a reduction in injurious falls resulting in fracture as reported in a similar study by Becker et al, ${ }^{26}$ but as the overall number of fractures was small it is likely to have been similarly underpowered to show a significant difference. As the RAC organization is now classifying four levels of injurious falls amalgamating them may provide larger sample sizes for future comparison.

We previously identified gaps in falls prevention policy, protocols and practice for CoP attention. ${ }^{20}$ However the pre-specified periods for CoP activity were found to be inadequate due to the unexpected need to extensively develop falls prevention policy and protocols prior to implementing interventions. A study reporting the potential of CoPs in nursing homes suggests allowing six months for implementation of an intervention but when development of an evidence-based protocol, such as falls prevention, is required a period of $18-36$ months is necessary, ${ }^{23}$ which we found to be the case in our study. A similar study in RAC where staff were participants in the process of implementing evidence-based interventions delivered the same finding that longer follow up was required. ${ }^{27}$ This extensive time requirement limited the ability of the $\mathrm{CoP}$ to deliver more multifactorial interventions in the short term hence the true impact on falls outcomes is likely not fully evident and requires longer term follow up. Additionally, as CoP members (staff)

\section{Implications}

As the RAC population continues to age and thus potentially acquire increased falls risk factors, a more realistic evaluation may be to focus on delivering a trend in fall reduction ${ }^{27}$ and injurious falls reduction, particularly fractures, as these are also more robustly measured, as suggested by other studies. ${ }^{5,14}$

Additional time for implementation and evaluation of falls prevention interventions will be required in complex settings such as RAC organizations. Sustainable models with flexibility are required to provide long term focus and follow up, as the constrained nature of the sector means that favorable outcomes delivered by external assistance, enabled through short term funding sources, is not able to be sustained. ${ }^{28,29} \mathrm{We}$ feel an operationalized CoP could offer a sustainable internal option for delivering falls prevention interventions but more time investment is required, so falls outcomes can continue to be measured.

In the absence of a RAC industry wide adoption of a accuracy of comparing injurious falls rates and injurious fall rates across the sector remains a challenge.

\section{Strengths and Limitations}

This study used a quasi-experimental pre-post design to accommodate 13 RAC sites that were pre-existing populations all doing some falls prevention interventions prior to the study commencing. Whilst this design does not have the rigor for generalization provided by the gold standard randomized controlled trial we, like Burland et al, ${ }^{5}$ felt this design provided a clear indication of intervention outcomes under "real world" conditions that are likely to be similar in other RAC settings.

We underestimated the requirement for long term follow up on falls outcomes (falls rates injurious falls rates). However it was difficult to plan for this prior to ascertaining the results of falls prevention site audits conducted following the standardized fall definition and injury classification the 
commencement of the larger project..$^{20}$

Changes in falls reporting during the trial is likely to have confounded fall rates as staff's clinical understanding of what constitutes a fall is likely to have influenced what events were actually recorded as falls. However the adoption of standardized falls reporting and classification ${ }^{24}$ is likely to rectify this in the longer term.

A falls prevention CoP delivering evidence based falls prevention interventions across $13 \mathrm{RAC}$ sites was unable to reduce falls rates after 18 months in operation although a reduction in the number of injurious falls resulting in fracture was observed. We were limited in our ability to gather more detailed resident level data, such as medication profiles, within the context of this study but plan to do so in future CoP activities. Measuring the effects of complex interventions in RAC settings when policy and protocols need development requires more time investment. However the falls prevention CoP was established as a potentially sustainable way of actioning and evaluating falls prevention activity and will continue to measure falls outcomes into the future.

\section{CONFLICTS OF INTEREST STASTEMENT}

The authors declared no potential conflicts of interest with respect to the research, authorship, and/or publication of this article.

\section{Funding}

The authors disclosed receipt of the following financial support for the research: This study has confirmed funding support from Collaborative Research Network (CRN) funding (Federal Government of Australia) as part of a project led by Associate Professor Anne-Marie Hill that was independently peer reviewed by the funder.

\section{Acknowledgements}

The authors thank the Brightwater Care Group for their support, especially the staff and members of the falls prevention community of practice.

\section{References}

01. Morley JE, Rolland Y, Tolson D, Vellas B. Increasing awareness of the factors producing falls: The mini falls assessment. $f \mathrm{Am} \mathrm{Med} \mathrm{Dir} \mathrm{Assoc.}$ 2012;13(2):87-90.

02. Oliver D, Connelly JB, Victor CR, Shaw FE, Whitehead A, Genc $\mathrm{Y}$ et al. Strategies to prevent falls and fractures in hospitals and care homes and effect of cognitive impairment: systematic review and metaanalyses. BMF. 2007;334(7584):82-7.

03. Rapp K, Becker C, Cameron ID, König H-H, Büchele G. Epidemiology of falls in residential aged care: analysis of more than 70,000 falls from residents of Bavarian nursing homes. $7 \mathrm{Am} \mathrm{Med} \mathrm{Dir}$ Assoc. 2012;13(2):187e1-e6.

04. Onder G, Carpenter I, Finne-Soveri H, Gindin J, Frijters D, Henrard $\mathrm{JC}$, et al. Assessment of nursing home residents in Europe: the Services and Health for Elderly in Long TERm care (SHELTER) study. BMC Health Serv Res. 2012;12(5):1-10.
05. Burland E, Martens P, Brownell M, Doupe M, Fuchs D. The evaluation of a fall management program in a nursing home population. Gerontologist. 2013;53(5):828-38.

06. Bradley C. Hospitalisations Due to Falls by Older People, Australia, 2009-10 (1742494145) 2013. Available at http://www.aihw.gov.au/ publication-detail/?id=60129542825. Accessed March 30, 2016.

07. Australian Institute of Health and Welfare. Residential aged care in Australia 2010-11: a statistical overview 2012. Available at http://www. aihw.gov.au/publication-detail/?id=10737422821. Accessed March 30, 2016.

08. Becker C, Rapp K. Fall prevention in nursing homes. Clin Geriatr Med. 2010;26(4):693-704.

09. Haines TP, Nitz J, Grieve J, Barker A, Moore K, Hill K, et al. Cost per fall: a potentially misleading indicator of burden of disease in health and residential care settings. f Eval Clin Pract. 2013;19(1):153-61.

10. Cameron ID, Murray GR, Gillespie LD, Robertson MC, Hill KD, Cumming RG, et al. Interventions for preventing falls in older people in nursing care facilities and hospitals. Cochrane Database Syst Rev. 2012;12:CD005465.

11. Vlaeyen E, Coussement J, Leysens G, Van der Elst E, Delbaere K, Cambier D, et al. Characteristics and effectiveness of fall prevention programs in nursing homes: A systematic review and meta-analysis of randomized controlled trials. 7 Am Geriatr Soc. 2015;63(2):211-21.

12. Panel on prevention of falls in older persons, American Geriatrics Society \& British Geriatrics Society. Summary of the updated American Geriatrics Society and British Geriatrics Society clinical practice guideline for the prevention of falls in older persons 2011.f Am Geriatr Soc. 201 1;49:664-72.

13. Australian Commission on Safety and Quality in Healthcare. Implementation guide for preventing falls and harm from falls in older people: Best practice guidelines for Australian Hospitals and Residential Aged Care Facilities 2009. Available at http://www.safetyandquality. gov.au/our-work/falls-prevention/falls-prevention-resources/. Accessed April 2, 2016.

14. Quigley P, Bulat T, Kurtzman E, Olney R, Powell-Cope G, Rubenstein L. Fall prevention and injury protection for nursing home residents. $\mathcal{f}$ Am Med Dir Assoc. 2010;11(4):284-93.

15. Ranmuthugala G, Cunningham FG, Plumb JJ, Long J, Georgiou A, Westbrook JI, et al. A realist evaluation of the role of communities of practice in changing healthcare practice. Implement Sci. 2011;6:49.

16. Francis-Coad J, Etherton-Beer C, Bulsara C, Nobre D, Hill AM. Investigating the impact of a falls prevention community of practice in a residential aged-care setting: a mixed methods study protocol. $\mathcal{f} A d v$ Nurs. 2015;71(12):2977-86.

17. Ranmuthugala G, Plumb JJ, Cunningham FC, Georgiou A, Westbrook JI, Braithwaite J. How and why are communities of practice established in the healthcare sector? A systematic review of the literature. $B M C$ Health Serv Res. 2011;11:273.

18. Pawson R, Tilley N. Realistic Evaluation. London: Sage; 1997.

19. Gray LC, Peel NM, Crotty M, Kurrle SE, Giles LC, Cameron ID. How effective are programs at managing transition from hospital to home? A case study of the Australian transition care program. BMC Geriatr. 2012;12(1):1.

20. Francis-Coad J, Etherton-Beer C, Bulsara C, Nobre D, Hill A-M. Using a community of practice to evaluate falls prevention activity in a residential aged care organization: a clinical audit. Aust Health Rev. 2016;41(1):13-8.

21. Wenger E. Communities of practice: Learning as a social system. Syst Thinker. 1998;9(5):2-3.

22. Barnett S, Jones SC, Caton T, Iverson D, Bennett S, Robinson L. Implementing a virtual community of practice for family physician training: a mixed-methods case study. 7 Med Internet Res. 2014;16(3):e83.

23. Tolson D, Lowndes A, Booth J, Schofield I, Wales A. The potential of 
communities of practice to promote evidence-informed practice within nursing homes. F Am Med Dir Assoc. 201 1;12(3):169-73.

24. Lamb SE, Jørstad-Stein EC, Hauer K, Becker C. Development of a common outcome data set for fall injury prevention trials: the Prevention of Falls Network Europe consensus. 7 Am Geriatr Soc. 2005;53(9):1618-22.

25. Kerse N, Butler M, Robinson E, Todd M. Fall prevention in residential care: a cluster, randomized, controlled trial. 7 Am Geriatr Soc. 2004; 52(4):524-31.

26. Becker C, Kron M, Lindemann U, Sturm E, Eichner B, Walter-Jung $\mathrm{B}$, et al. Effectiveness of a multifaceted intervention on falls in nursing home residents. $f$ Am Geriatr Soc. 2003;51(3):306-13.

27. Nitz J, Cyarto E, Andrews S, Fearn M, Fu S, Haines T, et al. Outcomes from the implementation of a facility-specific evidence-based falls prevention intervention program in residential aged care. Geriatr Nurs. 2012;33(1):41-50.

28. Ray WA, Taylor JA, Meador KG, Thapa PB, Brown AK, Kajihara $\mathrm{HK}$, et al. A randomized trial of a consultation service to reduce falls in nursing homes. FAMA. 1997;278(7):557-62.

29. Capezuti E, Taylor J, Brown H, Strothers HS, Ouslander JG. Challenges to implementing an APN-facilitated falls management program in long-term care. Appl Nurs Res. 2007;20(1):2-9. 